\title{
Rivaroxaban as an oral anticoagulant for stroke prevention in atrial fibrillation
}

This article was published in the following Dove Press journal:

Therapeutics and Clinical Risk Management

22 March 2014

Number of times this article has been viewed

\section{Alexander GG Turpie \\ Department of Medicine, McMaster University, Hamilton, ONT, Canada}

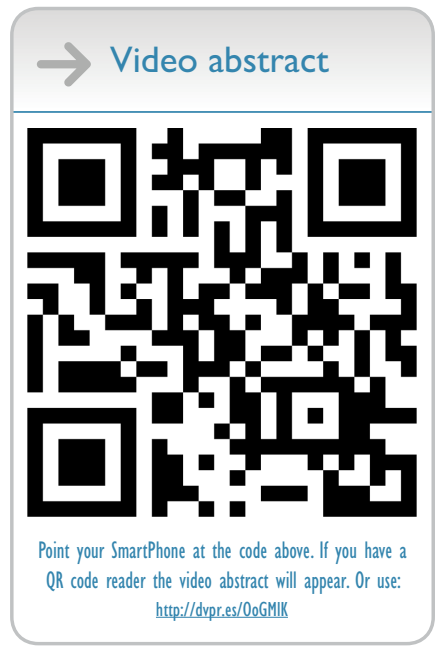

Correspondence: Alexander GG Turpie Department of Medicine, McMaster University, Hamilton Health Sciences-Hamilton General Hospital, 237 Barton Street East, Hamilton, ONT L8L 2X2, Canada

$\mathrm{Tel}+\mathrm{I} 4163636726$

Fax + I 9056289505

Email turpiea@mcmaster.ca
Abstract: Atrial fibrillation (AF) is the most common cardiac arrhythmia in the developed world and is associated with a fivefold increase in the risk of stroke, accounting for up to $15 \%$ of strokes in the general population. The European Society of Cardiology now recommends direct oral anticoagulants, such as rivaroxaban, apixaban, and dabigatran, in preference to vitamin $\mathrm{K}$ antagonist therapy for the prevention of stroke in patients with AF. This review focuses on the direct Factor Xa inhibitor rivaroxaban, summarizing the properties that make rivaroxaban appropriate for anticoagulant therapy in this indication (including its predictable pharmacokinetic and pharmacodynamic profile and once-daily dosing regimen) and describing data from the Phase III ROCKET AF trial, which showed once-daily rivaroxaban to be noninferior to warfarin for the prevention of stroke in patients with nonvalvular AF. In this trial, similar rates of major and nonmajor clinically relevant bleeding were observed; however, when compared with warfarin, rivaroxaban was associated with clinically significant reductions in intracranial and fatal bleeding. On the basis of these results, rivaroxaban was approved in both the United States and the European Union for the prevention of stroke and systemic embolism in patients with nonvalvular AF. Subanalyses of ROCKET AF data showed rivaroxaban to have consistent efficacy and safety across a wide range of patients, and studies to confirm these results in realworld settings are underway. This review also describes practical considerations for treatment with rivaroxaban in clinical practice (including dose reductions in specific high-risk patients, eg, those with renal impairment), recommendations for the transition from vitamin $\mathrm{K}$ antagonists to rivaroxaban, the management of bleeding events, and the measurement of rivaroxaban exposure.

Keywords: atrial fibrillation, stroke, rivaroxaban, anticoagulation

\section{Introduction}

In the past 5 years, the oral, direct Factor Xa inhibitor rivaroxaban ${ }^{1}$ has been approved in five different thromboembolic indications for seven different areas of use (listed in Table 1). ${ }^{2,3}$ The indication on which this article focuses is the reduction of stroke and systemic embolism in patients with nonvalvular atrial fibrillation (AF), for which rivaroxaban has been approved in the United States (US) and the European Union (EU) at a dose of $20 \mathrm{mg}$ once daily (15 mg once daily in patients with creatinine clearance [CrCl] $15-50 \mathrm{~mL} / \mathrm{minute}$ and $15-49 \mathrm{~mL} /$ minute in the US and EU, respectively). ${ }^{2-4}$

$\mathrm{AF}$ is the most common cardiac arrhythmia and is a major risk factor for stroke and systemic embolism. The prevalence of AF in the general population of the developed world is $1.5 \%-2.0 \%$; in the US alone, more than 2 million people are affected by this condition. Adults aged 40 years or older have a one in four risk for developing AF; the 
Table I Dosing regimens of rivaroxaban in adult patients for approved indications in the European Union and the US

\begin{tabular}{|c|c|c|}
\hline Approved indications & European Union & US \\
\hline $\begin{array}{l}\text { Prevention of stroke and } \\
\text { systemic embolism in } \\
\text { patients with nonvalvular AF }\end{array}$ & $\begin{array}{l}20 \mathrm{mg} \text { od } \\
\text { (I5 mg od in } \\
\text { patients with } \mathrm{CrCl} \\
15-49 \mathrm{~mL} / \text { minute) }\end{array}$ & $\begin{array}{l}20 \mathrm{mg} \text { od } \\
\text { (I5 mg od in } \\
\text { patients with } \mathrm{CrCl} \\
15-50 \mathrm{~mL} / \text { minute) }\end{array}$ \\
\hline $\begin{array}{l}\text { VTE prevention after } \\
\text { elective hip or knee } \\
\text { replacement surgery }\end{array}$ & $10 \mathrm{mg}$ od & $10 \mathrm{mg}$ od \\
\hline Treatment of DVT or PE & $\begin{array}{l}15 \mathrm{mg} \text { bid for } \\
3 \text { weeks } \\
20 \mathrm{mg} \text { od } \\
\text { thereafter }\end{array}$ & $\begin{array}{l}15 \mathrm{mg} \text { bid for } \\
3 \text { weeks } \\
20 \mathrm{mg} \text { od } \\
\text { thereafter }\end{array}$ \\
\hline $\begin{array}{l}\text { Prevention of recurrent } \\
D V T \text { and PE }\end{array}$ & $20 \mathrm{mg}$ od & $20 \mathrm{mg}$ od \\
\hline $\begin{array}{l}\text { Prevention of } \\
\text { atherothrombotic events } \\
\text { in patients with ACS with } \\
\text { elevated cardiac biomarkers* }\end{array}$ & $2.5 \mathrm{mg}$ bid & Not approved \\
\hline
\end{tabular}

Note: *Rivaroxaban is coadministered with acetylsalicylic acid alone or with acetylsalicylic acid plus clopidogrel or ticlopidine. Data from references 2 and 3.

Abbreviations: ACS, acute coronary syndrome; AF, atrial fibrillation; bid, twice daily; $\mathrm{CrCl}$, creatinine clearance; DVT, deep vein thrombosis; od, once daily; PE, pulmonary embolism; US, United States; VTE, venous thromboembolism.

average age of patients with AF is $75-85$ years, and the prevalence of AF is approximately $10 \%$ in patients aged 85 years and older. ${ }^{5-7}$ Compared with the general population, patients with $\mathrm{AF}$ have a fivefold increase in the risk of stroke. ${ }^{8}$ Moreover, $\mathrm{AF}$ is associated with a threefold increase in the incidence of congestive heart failure, ${ }^{6}$ a risk that is even higher in patients older than 80 years of age. ${ }^{8}$ In patients with $\mathrm{AF}$, stroke is associated with a poorer prognosis, an increased rate of medical and neurological complications, and a higher in-hospital mortality than it is in patients without AF. ${ }^{9}$ After an AF-related stroke, almost $50 \%$ of patients die within 1 year; ${ }^{10}$ furthermore, among patients with AF who were admitted to the hospital with a first ischemic stroke, $60 \%$ of strokes were disabling and $20 \%$ of stokes were fatal. ${ }^{11}$ Owing to the substantial increase in the risk of stroke in patients with $\mathrm{AF}$, anticoagulants that target multiple components in the coagulation cascade, such as the vitamin $\mathrm{K}$ antagonist (VKA) warfarin, have become the mainstay of therapy for stroke prevention in patients with nonvalvular AF., ${ }^{8}$ However, warfarin is associated with many limitations, including the need for regular coagulation monitoring. The effects of warfarin are influenced by numerous food and drug interactions as well as by genetic variations, which can result in an unpredictable response. ${ }^{13,14}$ This has prompted the development of target-specific oral anticoagulants, including the
Factor Xa inhibitors rivaroxaban, apixaban, and edoxaban, and the thrombin inhibitor dabigatran etexilate.

The objective of this review is to provide an overview of the pharmacological characteristics of rivaroxaban and its practical implementation as a once-daily oral anticoagulant with minimal drug-drug interactions and without a need for routine coagulation monitoring for stroke prevention in patients with nonvalvular AF.

\section{Guidelines for stroke prevention in atrial fibrillation}

Current guidelines for the management of patients with AF recommend long-term oral anticoagulant therapy based on respective stroke risk. ${ }^{6,15}$

Recommendations from the European Society of Cardiology $(\mathrm{ESC})^{6}$ are based on the $\mathrm{CHA}_{2} \mathrm{DS}_{2}-\mathrm{VASc}$ scoring system (congestive heart failure/left ventricular dysfunction, hypertension, age $\geq 75$ years [2 points], diabetes, stroke [2 points], vascular disease, age 65-74 years, sex category [female]), which is more sensitive for the detection of truly low-risk patients with AF than is the more widely used $\mathrm{CHADS}_{2}$ scoring system (congestive heart failure, hypertension, age $\geq 75$ years, diabetes mellitus, prior stroke or transient ischemic attack [TIA; 2 points]). According to the ESC guidelines, the use of oral anticoagulation therapy with rivaroxaban, dabigatran, or apixaban is recommended in preference to the use of a VKA in patients with nonvalvular $\mathrm{AF}$ and a $\mathrm{CHA}_{2} \mathrm{DS}_{2}-\mathrm{VASc}$ score $\geq 2$. In patients with a $\mathrm{CHA}_{2} \mathrm{DS}_{2}-\mathrm{VASc}$ score of 1 , oral anticoagulation therapy should be considered on the basis of risk for bleeding complications and patient preference, but no therapy should be considered if the score of 0 or 1 is based on female sex. The ESC recommends using antiplatelet therapy (with acetylsalicylic acid [ASA] plus clopidogrel or ASA alone) only in patients who refuse or cannot tolerate oral anticoagulants for reasons other than bleeding. ${ }^{6}$

Guidelines from the American College of Chest Physicians ${ }^{15}$ are based on risk stratification of patients according to the $\mathrm{CHADS}_{2}$ scoring system. These guidelines recommend anticoagulation with dabigatran or warfarin in patients with a $\mathrm{CHADS}_{2}$ score of $\geq 2$ and consider rivaroxaban and apixaban as reasonable alternatives. In patients who are not suitable for oral anticoagulation, ASA plus clopidogrel may be considered. Individualized treatment approaches are recommended for patients with a $\mathrm{CHADS}_{2}$ score $<2 .{ }^{15}$ 


\section{Rivaroxaban: a once-daily oral anticoagulant}

Rivaroxaban directly inhibits both free and clot-bound Factor Xa and prevents the formation of new clots and the extension of existing clots. ${ }^{1}$ Rivaroxaban is absorbed rapidly from the gastrointestinal tract ${ }^{16}$ and reaches peak plasma concentrations within 2-4 hours. ${ }^{17,18}$ Maximum inhibition of Factor Xa activity, prolongation of prothrombin time (PT; with a sensitive thromboplastin reagent), and prolongation of activated partial thromboplastin time (which is less predictable) ${ }^{19}$ all occur approximately $2-3$ hours after dosing; however, measurements can vary depending on the reagents used. ${ }^{17,20}$ Rivaroxaban has a half-life of 5-9 hours in healthy subjects and 11-13 hours in elderly patients. ${ }^{2,18,20}$ Furthermore, rivaroxaban has predictable pharmacokinetics and pharmacodynamics ${ }^{21-23}$ and minimal food and drug interactions. Importantly, rivaroxaban has a dual mode of elimination: one-third is eliminated as unchanged drug in the urine; two-thirds undergoes metabolic degradation in the liver, half of which is excreted via the kidneys and half via the hepatobiliary route. ${ }^{2,20,24}$ High oral bioavailability (80\%-100\%) of rivaroxaban (at doses of $2.5 \mathrm{mg}$ and $10.0 \mathrm{mg}$ ) is achieved irrespective of fasting or fed conditions, and this high bioavailability continues up to a dose of $15.0 \mathrm{mg}$. Bioavailability and absorption decrease at higher doses of rivaroxaban; however, this decrease is less pronounced if the dose is taken with food. ${ }^{2,25}$

Patients with AF are frequently elderly and have one or more comorbidities requiring additional medications. Rivaroxaban is contraindicated in patients with hypersensitivity to the active substance or to any of the excipients, in patients with clinically significant active bleeding, and in patients with hepatic disease associated with coagulopathy and clinically relevant bleeding risk, including cirrhotic patients with moderate or severe hepatic impairment (classified as Child-Pugh B or C). Furthermore, rivaroxaban is contraindicated in women who are pregnant or breastfeeding. ${ }^{2}$ Care should also be exercised with co-medications: because rivaroxaban is a substrate of both cytochrome P450 3A4 and P-glycoprotein, systemic treatment with drugs that are strong inducers or inhibitors of cytochrome P4503A4 or P-glycoprotein (such as ketoconazole, itraconazole, voriconazole, posaconazole, or ritonavir) is not recommended because coadministration of these drugs may increase the risk of bleeding. Drugs that may reduce the plasma concentration of rivaroxaban below its effective concentration (such as rifampicin, phenytoin, carbamazepine, phenobarbital, or St John's wort) should be used with caution. ${ }^{2}$
Rivaroxaban is one of three direct oral anticoagulants that have been approved for the prevention of (EU) or reduction in the risk for (US) stroke and systemic embolism in patients with nonvalvular AF (Table 2), ${ }^{2,3}$ When treating with rivaroxaban, physicians must consider the patient's renal function. In patients with $\mathrm{AF}$ and normal renal function, rivaroxaban is recommended at a dose of $20 \mathrm{mg}$ once daily. However, in the EU, rivaroxaban is not recommended in patients with $\mathrm{CrCl}$ below $15 \mathrm{~mL} /$ minute, and a reduced dose of $15 \mathrm{mg}$ once daily is recommended in patients with mild or moderate renal impairment ( $\mathrm{CrCl} 15-49 \mathrm{~mL} /$ minute). In the US, the recommendations differ slightly with respect to categories of renal impairment (Table 2).

Patient characteristics need to be taken into account when considering dose reductions for all direct oral anticoagulants (Table 2).

\section{Rivaroxaban in atrial fibrillation: the ROCKET AF trial}

ROCKET AF was a large, international, randomized, double-blind, event-driven Phase III study of 14,264 patients with nonvalvular AF, comparing once-daily rivaroxaban with dose-adjusted warfarin. Patients were randomized to receive either rivaroxaban $20 \mathrm{mg}$ once daily (or $15 \mathrm{mg}$ once daily in patients with $\mathrm{CrCl} 30-49 \mathrm{~mL} /$ minute at screening) or dose-adjusted warfarin (international normalized ratio [INR] 2.0-3.0). ${ }^{4}$

In this study, the median patient age was 73 years, and $39.7 \%$ of patients were women. The mean $\mathrm{CHADS}_{2}$ score was 3.5 and more than $86.9 \%$ of patients had a $\mathrm{CHADS}_{2}$ score of $\geq 3$. The median $\mathrm{CrCl}$ was $67 \mathrm{~mL} /$ minute. Prior to enrollment in ROCKET AF, $62.4 \%$ of patients had been treated with a VKA. The patients had high rates of coexisting conditions, including previous stroke, systemic embolism, or TIA (54.8\%), previous heart failure (62.5\%), hypertension $(90.5 \%)$, and diabetes $(40.0 \%)$.

The primary efficacy endpoint was the composite of stroke (ischemic or hemorrhagic) and systemic embolism. In the primary efficacy analysis of the per-protocol as-treated population, this endpoint occurred at a rate of $1.7 \%$ year in the rivaroxaban arm and 2.2\%/year in the warfarin arm (hazard ratio $[\mathrm{HR}]=0.79 ; 95 \%$ confidence interval $[\mathrm{CI}]=0.66 \%-0.96 \%$; $P<0.001$ for noninferiority). In the as-treated safety population, rivaroxaban demonstrated superior efficacy, with primary endpoints occurring at a rate of $1.7 \% /$ year and $2.2 \% /$ year in the rivaroxaban and warfarin arms, respectively $(\mathrm{HR}=0.79 ; 95 \% \mathrm{CI}$ $=0.65 \%-0.95 \% ; P=0.02$ for superiority). In the intent-to-treat 
Table 2 Dosing regimens of apixaban, dabigatran, and rivaroxaban for the prevention of stroke in patients with AF in the European Union and US

\begin{tabular}{|c|c|c|c|}
\hline & Apixaban & Dabigatran & Rivaroxaban \\
\hline \multicolumn{4}{|l|}{ European Union } \\
\hline Recommended & $5 \mathrm{mg}$ bid in patients with & $150 \mathrm{mg}$ bid in patients with & $20 \mathrm{mg}$ od in patients with \\
\hline dose & $\mathrm{CrCl} \geq 30 \mathrm{~mL} /$ minute & $\mathrm{CrCl} \geq 30 \mathrm{~mL} /$ minute & $\mathrm{CrCl} \geq 50 \mathrm{~mL} /$ minute \\
\hline Dose adjustments & $\begin{array}{l}2.5 \mathrm{mg} \text { bid if } \mathrm{CrCl} 15-29 \mathrm{~mL} / \mathrm{minute} \text {; } \\
2.5 \mathrm{mg} \text { bid in the presence of } \geq 2 \text { of the } \\
\text { following characteristics: } \\
\text { - Age } \geq 80 \text { years } \\
\text { - Body weight } \leq 60 \mathrm{~kg} \\
\text { - Serum creatinine } \geq 1.5 \mathrm{mg} / \mathrm{dL}(133 \mu \mathrm{mol} / \mathrm{L})\end{array}$ & $\begin{array}{l}\text { I } 10 \text { mg bid may be considered in } \\
\text { patients with the following factors: } \\
\text { - Age } \geq 80 \text { years (or } 75-80 \text { years } \\
\text { with high risk of bleeding) } \\
\text { - } \mathrm{CrCl} 30-50 \mathrm{~mL} / \text { minute with a } \\
\text { high risk of bleeding }\end{array}$ & $\begin{array}{l}15 \mathrm{mg} \text { od if } \mathrm{CrCl} \\
15-49 \mathrm{~mL} / \text { minute }\end{array}$ \\
\hline $\begin{array}{l}\text { Contraindicated in } \\
\text { patients with } \mathrm{CrCl}\end{array}$ & $\begin{array}{l}\text { No contraindications but not recommended } \\
\text { in patients with } \mathrm{CrCl}<15 \mathrm{~mL} / \text { minute }\end{array}$ & $<30 \mathrm{~mL} /$ minute & $\begin{array}{l}\text { No contraindications but not } \\
\text { recommended in patients } \\
\text { with } \mathrm{CrCl}<\mathrm{I} 5 \mathrm{~mL} / \text { minute }\end{array}$ \\
\hline \multicolumn{4}{|l|}{ US } \\
\hline $\begin{array}{l}\text { Recommended } \\
\text { dose }\end{array}$ & $5 \mathrm{mg}$ bid in patients with $\mathrm{CrCl} \geq 15 \mathrm{~mL} /$ minute & $\begin{array}{l}\text { I } 50 \mathrm{mg} \text { bid in patients with } \mathrm{CrCl} \\
>30 \mathrm{~mL} / \text { minute (unless concomitantly } \\
\text { using P-gp inhibitors; see dose adjustments) }\end{array}$ & $\begin{array}{l}20 \mathrm{mg} \text { od in patients with } \\
\mathrm{CrCl}>50 \mathrm{~mL} / \text { minute }\end{array}$ \\
\hline Dose adjustments & $\begin{array}{l}2.5 \mathrm{mg} \text { bid in the presence of } \geq 2 \text { of } \\
\text { the following characteristics: } \\
\text { - Age } \geq 80 \text { years } \\
\text { - Body weight } \leq 60 \mathrm{~kg} \\
\text { - Serum creatinine } \geq 1.5 \mathrm{mg} / \mathrm{dL}(\mathrm{I} 33 \mu \mathrm{mol} / \mathrm{L})\end{array}$ & $\begin{array}{l}75 \mathrm{mg} \text { bid if } \mathrm{CrCl} \text { I5-30 mL/minute or } \\
\text { in patients with } \mathrm{CrCl} 30-50 \mathrm{~mL} / \text { minute } \\
\text { concomitantly using P-gp inhibitors } \\
\text { (eg, dronedarone or systemic } \\
\text { ketoconazole) }\end{array}$ & $\begin{array}{l}15 \mathrm{mg} \text { od if } \mathrm{CrCl} \\
15-50 \mathrm{~mL} / \text { minute }\end{array}$ \\
\hline $\begin{array}{l}\text { Contraindicated in } \\
\text { patients with } \mathrm{CrCl}\end{array}$ & $\begin{array}{l}\text { No contraindications but not recommended } \\
\text { in patients with } \mathrm{CrCl}<15 \mathrm{~mL} / \text { minute }\end{array}$ & $\begin{array}{l}\text { Avoid use in patients with } \mathrm{CrCl} \\
\mathrm{I} 5-30 \mathrm{~mL} / \text { minute and concomitantly } \\
\text { receiving } \mathrm{P} \text {-gp inhibitors; no } \\
\text { recommendations are available for } \\
\text { patients with } \mathrm{CrCl}<15 \mathrm{~mL} / \text { minute }\end{array}$ & $<15 \mathrm{~mL} /$ minute \\
\hline
\end{tabular}

Note: Data from references 2, 3, and 5I-54.

Abbreviations: AF, atrial fibrillation; bid, twice daily; $\mathrm{CrCl}$, creatinine clearance; od, once daily; P-gp, P-glycoprotein; US, United States.

population, rivaroxaban was noninferior to warfarin for the primary efficacy endpoint $(\mathrm{HR}=0.88 ; 95 \% \mathrm{CI}=0.75 \%-1.03 \%$; $P<0.001$ for noninferiority). The event rates of all-cause deaths and myocardial infarction were lower in the rivaroxaban group than in the warfarin group; however, these reductions were not statistically significant. The principal safety endpoint of major and nonmajor clinically relevant bleeding was similar in both treatment groups, occurring at a rate of $14.9 \%$ year in patients receiving rivaroxaban and at $14.5 \%$ /year in patients receiving warfarin $(P=0.44)$ (Table 3)., ${ }^{4,26,27}$ Rates of any major bleeding events were also similar in both treatment groups $(3.6 \%$ in the rivaroxaban group and $3.4 \%$ in the warfarin group; $P=0.58$ ). Rivaroxaban was associated with significant reductions in the rates of intracranial hemorrhage (ICH; $0.5 \%$ versus $0.7 \%$; $P=0.02)$ and fatal bleeding $(0.2 \%$ versus $0.5 \% ; P=0.003)$ when compared with warfarin. ${ }^{4}$ Major bleeding from a gastrointestinal site $(3.2 \%$ versus $2.2 \% ; P<0.001)$ and the need for transfusion $(2.6 \%$ versus $2.1 \% ; P=0.04)$ were more common in the rivaroxaban group than the warfarin group.

The dosing regimen for ROCKET AF (20 mg once daily; $15 \mathrm{mg}$ once daily in patients with $\mathrm{CrCl} 30-49 \mathrm{~mL} /$ minute) was based on Phase II dose-finding studies in patients treated for acute deep vein thrombosis and on exposure simulations in patients with $\mathrm{AF}^{23,24,28}$ The simulations in virtual patient populations with $\mathrm{AF}$ showed that a rivaroxaban dose of $15 \mathrm{mg}$ once daily in patients with $\mathrm{CrCl} 30-49 \mathrm{~mL} /$ minute would achieve exposure similar to that observed with $20 \mathrm{mg}$ once daily in patients with normal renal function. ${ }^{23}$ In summary, rivaroxaban can be administered orally as a fixed once-daily dose and without routine coagulation monitoring; dose adjustment is only required in the treatment of $\mathrm{AF}$ patients with moderateto-severe renal impairment. ${ }^{25}$ The Phase III ROCKET AF trial successfully tested and validated the reduced dose of $15 \mathrm{mg}$ once daily for patients with renal impairment $(\mathrm{CrCl} 30-49 \mathrm{~mL} /$ minute), resulting in the subsequent approval of this dose. ${ }^{4}$

When analyzing outcomes of ROCKET AF according to patient age or $\mathrm{CHADS}_{2}$ score, rivaroxaban demonstrated consistent noninferior efficacy and a similar safety profile compared with warfarin., ${ }^{4,29}$ Furthermore, prespecified subgroup analyses compared the efficacy and safety outcomes in patients with moderate renal impairment ( $\mathrm{CrCl} 30-49 \mathrm{~mL} /$ minute; rivaroxaban group receiving $15 \mathrm{mg}$ once daily) with those in patients with normal renal function (rivaroxaban group receiving $20 \mathrm{mg}$ once daily) ${ }^{26} \mathrm{in}$ 
Table 3 Summary of efficacy and safety results in ROCKET AF and in subgroup analyses (event rate per 100 patient-years of follow-up; percentage of events per year)

\begin{tabular}{|c|c|c|c|c|c|c|c|c|}
\hline \multirow[t]{2}{*}{ Study } & \multicolumn{4}{|c|}{ Primary efficacy endpoint* } & \multicolumn{4}{|c|}{ Principal safety endpoint ${ }^{\dagger}$} \\
\hline & Rivaroxaban & Warfarin & HR (95\% Cl) & $P$-value & Rivaroxaban & Warfarin & HR $(95 \% \mathrm{Cl})$ & P-va \\
\hline \multicolumn{9}{|c|}{ ROCKET AF: per-protocol, as-treated study population for primary efficacy endpoint; safety, as-treated population for principal safety endpoint ${ }^{4}$} \\
\hline Overall & 1.7 & 2.2 & $0.79(0.66-0.96)$ & $\begin{array}{l}<0.001 \text { (for } \\
\text { noninferiority) }\end{array}$ & 14.9 & 14.5 & $1.03(0.96-1.11)$ & 0.44 \\
\hline \multicolumn{9}{|c|}{$\begin{array}{l}\text { Renal function subgroups: per-protocol, as-treated study population for primary efficacy endpoint; safety, as-treated population for principal safety } \\
\text { endpoint }^{26}\end{array}$} \\
\hline $\mathrm{CrCl} 30-49 \mathrm{~mL} /$ minute $\neq$ & & 2.77 & $0.84(0.57-1.23)$ & $0.76^{\S}$ & 17.82 & 18.28 & $0.98(0.84-1.14)$ & 0.449 \\
\hline $\mathrm{CrCl} \geq 50 \mathrm{~mL} /$ minute & 1.57 & 2.00 & $0.78(0.63-0.98)$ & & 14.24 & 13.67 & $1.04(0.96-1.13)$ & \\
\hline \multicolumn{9}{|c|}{$\begin{array}{l}\text { History of previous stroke or TIA: intent-to-treat population for primary efficacy endpoint; safety, as-treated population for principal safety } \\
\text { endpoint }^{27}\end{array}$} \\
\hline No & & 1.88 & $0.77(0.58-1.01)$ & 0.23 & 16.69 & 15.19 & $1.10(0.99-1.21)$ & 0.08 \\
\hline Yes & 2.79 & 2.96 & $0.94(0.77-1.16)$ & & $13.3 \mid$ & 13.87 & $0.96(0.87-1.07)$ & \\
\hline \multicolumn{9}{|c|}{$\begin{array}{l}\text { VKA-naïve or VKA-experienced patients: intent-to-treat population for primary efficacy endpoint; safety, as-treated population for principal safety } \\
\text { endpoint }^{31}\end{array}$} \\
\hline VKA-naïve & 2.32 & 2.87 & $0.81(0.64-1.03)$ & 0.36 & II.20" & 12.87 & $0.84(0.74-0.95)$ & 0.003 \\
\hline VKA-experienced & 1.98 & 2.09 & $0.94(0.75-1.18)$ & & $|4.73| \mid$ & 14.28 & $1.06(0.96-1.17)$ & \\
\hline \multicolumn{9}{|c|}{ Patients with or without HF: intent-to-treat population for primary efficacy endpoint; safety, as-treated population for principal safety endpoint ${ }^{30}$} \\
\hline With HF & 1.90 & 2.09 & $0.91(0.74-1.13)$ & 0.62 & 14.22 & 14.02 & $1.05(0.95-1.15)$ & 0.99 \\
\hline Without HF & 2.10 & 2.54 & $0.84(0.65-1.09)$ & & 16.12 & 15.35 & $1.05(0.93-1.18)$ & \\
\hline
\end{tabular}

Notes: *Composite of stroke and systemic embolism; ${ }^{\dagger}$ Composite of major and nonmajor clinically relevant bleeding; ${ }^{\ddagger} 15 \mathrm{mg}$ od; $\$ P$-values are the same for $\mathrm{CrCl} 30-49 \mathrm{~mL} / \mathrm{minute}$ and $\mathrm{CrCl} \geq 50 \mathrm{~mL} /$ minute; "Composite of major and nonmajor clinically relevant bleeding 30 days after randomization. Data from references 4, 26, 27 and 31 . Copyright $\odot$ 2013. Wolters Kluwer Health. Adapted with permission from van Diepen S, Hellkamp AS, Patel MR, et al. Efficacy and safety of rivaroxaban in patients with heart failure and

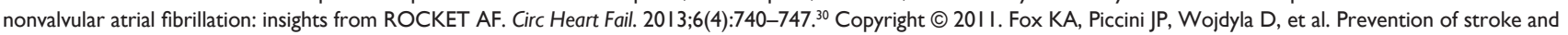
systemic embolism with rivaroxaban compared with warfarin in patients with non-valvular atrial fibrillation and moderate renal impairment. Eur Heart J. 20I I;32(19):2387-2394, by permission of Oxford University Press, http://eurhearti.oxfordjournals.org/content/early/201//08/26/eurhearti.ehr342.full. Permission must be obtained from Oxford University Press for any onwards reuse of the figure. ${ }^{26}$

Abbreviations: $\mathrm{Cl}$, confidence interval; $\mathrm{CrCl}$, creatinine clearance; $\mathrm{HF}$, heart failure; $\mathrm{HR}$, hazard ratio; od, once daily; TIA, transient ischemic attack; VKA, vitamin $\mathrm{K}$ antagonist.

patients with and without previous stroke or TIA, ${ }^{27}$ in patients with and without heart failure and $\mathrm{AF}^{30}$ and in VKA-naïve and VKA-experienced patients. ${ }^{31}$ These analyses showed no differences in efficacy outcomes when both treatment arms were compared and showed similar or lower rates of bleeding with rivaroxaban, thereby confirming the overall results of ROCKET AF and supporting the use of rivaroxaban as an alternative treatment option to warfarin for the prevention of stroke and systemic embolism in these subgroups of patients with AF (Table 3). In addition, the results of one study, which provided a benefit-risk assessment of the effect of reduceddose rivaroxaban compared with warfarin (in patients with moderate renal insufficiency), demonstrated that patients with renal impairment have a higher risk of stroke and systemic embolism than patients with normal renal function, independent of the anticoagulant administered. ${ }^{26}$

A post hoc analysis of patients with AF who were enrolled in ROCKET AF demonstrated that, while on treatment, patients with prior myocardial infarction receiving rivaroxaban had fewer ischemic cardiac events than those receiving warfarin. ${ }^{32}$

At the end of the study period of ROCKET AF, participating sites were notified and patients in the intent-to-treat population were switched to open-label conventional anticoagulants. As per study design, patients on warfarin continued to receive the drug whereas patients in the rivaroxaban group discontinued rivaroxaban and started warfarin therapy, resulting in a period of inadequate anticoagulation in these patients. This transitioning protocol explains differences between treatment groups in the median times to reach therapeutic INR, namely 13 days for patients in the rivaroxaban group compared with 3 days for patients in the warfarin group. Patients in the rivaroxaban group had a significantly higher event rate during the end-of-study transition period (day 2 to day 30 after study end) compared with patients in the warfarin group ( 22 versus $7 ; P=0.008$ ).

A separate prospective, randomized, double-blind, Phase III safety trial in 1,280 Japanese patients with AF and a moderate-to-high risk of stroke (mean $\mathrm{CHADS}_{2}$ score 3.25), J-ROCKET AF compared the safety of rivaroxaban $15 \mathrm{mg}$ once daily $(10 \mathrm{mg}$ once daily for patients with $\mathrm{CrCl}$ 30-49 $\mathrm{mL} /$ minute) with dose-adjusted warfarin according to Japanese guidelines (target INR of 2.0-3.0 in patients aged $<70$ years; a reduced target INR of 1.6-2.6 in patients aged $\geq 70$ years).$^{33}$ This study demonstrated the noninferiority of rivaroxaban to warfarin for the principal safety outcome of major and nonmajor clinically relevant bleeding 
in the on-treatment safety population $(18.04 \% /$ year versus $16.42 \%$ /year; $\mathrm{HR}=1.11 ; 95 \% \mathrm{CI}=0.87 \%-1.42 \% ; P<0.001)$. There was a strong trend for a reduction in the rate of the primary efficacy endpoint in the per-protocol as-treated population (defined as the composite of stroke and systemic embolism) with rivaroxaban versus warfarin $(\mathrm{HR}=0.49$; $P=0.050)$. Rates of ICH were lower in the rivaroxaban group than the warfarin group $(0.8 \%$ /year versus $1.6 \%$ year $)$. Similarly, the rate of the composite secondary efficacy endpoint of stroke, non-central-nervous-system systemic embolism, and vascular death was lower in the rivaroxaban group than the warfarin group (1.8\%/year versus $2.9 \%$ /year; $\mathrm{HR}=0.65 ; 95 \% \mathrm{CI}=0.34 \%-1.22 \%) .{ }^{33}$

\section{Real-world experience}

Clinical trial criteria do not always reflect real-world settings because they select patients according to strict inclusion/ exclusion criteria and prespecify the active comparator and treatment approach, including duration, intervention, and outcome measures. Phase IV nonintervention studies have an important role in assessing the efficacy and safety of newly approved drugs in routine clinical practice.

The aim of the ongoing nonintervention XANTUS study ${ }^{34}$ is to evaluate the effectiveness of rivaroxaban for the prevention of stroke and non-central-nervous-system systemic embolism in patients with nonvalvular AF in real-world clinical practice, with an estimated enrollment of 6,000 patients. Additional real-world studies are underway.

\section{Practical considerations}

There are a number of practical aspects to take into account when considering rivaroxaban therapy for the prevention of stroke and systemic embolism in patients with nonvalvular AF. The necessity for dose reductions in patients with renal impairment has already been covered in detail., ${ }^{4,26}$ Some clinical scenarios, such as surgical interventions or invasive procedures, may require patients to delay the next rivaroxaban dose to minimize risk of bleeding. Where possible, interventions should be carried out at trough rivaroxaban plasma concentrations and avoided at peak rivaroxaban plasma concentrations. After the intervention, rivaroxaban should be restarted as soon as possible to minimize time without anticoagulation. ${ }^{19}$ In cases in which there are problems with adherence to or compatibility with a VKA, it may be advantageous to switch patients to rivaroxaban. In ROCKET AF, the higher event rate when switching patients from rivaroxaban to warfarin during the end-of-study transition period highlights the importance of carefully monitoring the anticoagulation status of individual patients to ensure adequate anticoagulation during transition. ${ }^{4}$ Recommendations for switching strategies were recently published. ${ }^{19}$ In summary, when transitioning patients from rivaroxaban to VKAs, VKA therapy should be initiated while patients continue on rivaroxaban and until the INR is $\geq 2$.0, at which point rivaroxaban can be discontinued. When transitioning from a VKA to rivaroxaban, once the INR is $\leq 3.0$ after stopping VKA, rivaroxaban can be initiated at the recommended dose. ${ }^{2}$ Pharmacokinetic properties of the specific VKA must be considered during transition, in addition to the bleeding risk of the patient. ${ }^{19}$

Other aspects, such as the optimal timing of initiating therapy after a stroke or $\mathrm{ICH}$, are currently unresolved. Standard procedures are in place for the management of minor to moderate bleeding events. ${ }^{2}$ In rare cases of severe, life-threatening bleeding events, the use of a reversal agent may be beneficial. Reversal agents, such as prothrombin complex concentrate, activated prothrombin complex concentrate, and recombinant Factor VIIa, have been evaluated principally for their potential to reverse the anticoagulant activity of rivaroxaban in ex vivo or animal studies. Data from studies in healthy volunteers are also available. ${ }^{35-38}$ Additionally, a recombinant form of Factor Xa, the r-Antidote andexanet alfa (PRT064445; Portola Pharmaceuticals Inc., South San Francisco, CA, USA), which is catalytically inactive but retains its ability to bind direct Factor Xa inhibitors, has been evaluated as a reversal agent for the new oral anticoagulants. ${ }^{39}$ This study demonstrated that r-Antidote has the potential to neutralize rivaroxaban, betrixaban, and apixaban in animal models. ${ }^{39}$ Clinical trials are currently underway to evaluate the reversal potential of agents for several anticoagulants in vivo and in patients with life-threatening bleeding. ${ }^{40,41}$

Rivaroxaban does not require routine coagulation monitoring but some clinical situations may require measurement of rivaroxaban exposure, eg, in patients with suspected overdose or if noncompliance is suspected, in patients who require emergency surgery, or in patients with a thromboembolic or hemorrhagic event. ${ }^{19}$ Routine coagulation assays, such as PT and activated partial thromboplastin time, are not suitable for the quantitative assessment of rivaroxaban exposure because they do not reflect plasma levels of rivaroxaban. ${ }^{42-45}$ Importantly, owing to their different response sensitivities to rivaroxaban, different PT reagents will yield markedly varied PT results. PT assays that predominantly use Neoplastin Plus (Roche Diagnostics, Mannheim, Germany) provide a qualitative measurement, whereas anti-Factor Xa chromogenic assays measure rivaroxaban concentrations quantitatively. ${ }^{19,46-49}$ Both of these laboratory assays have 
Table 4 Recommendations, advantages, and disadvantages of laboratory assays for measuring rivaroxaban exposure

\begin{tabular}{|c|c|c|c|}
\hline Assay & Recommendations & Advantages & Disadvantages \\
\hline $\begin{array}{l}\text { Anti-Factor } \\
\text { Xa chromogenic } \\
\text { assay }\end{array}$ & $\begin{array}{l}\text { - This assay is recommended } \\
\text { (over PT measurement) and } \\
\text { should always be used if possible }\end{array}$ & $\begin{array}{l}\text { - Specific and sensitive quantitative } \\
\text { measure } \\
\text { - Determines plasma levels after } \\
\text { all approved therapeutic doses of } \\
\text { rivaroxaban have been administered } \\
\text { - Rivaroxaban calibrators and controls } \\
\text { are commercially available }\end{array}$ & $\begin{array}{l}\text { - Requires rivaroxaban calibrators and controls } \\
\text { - Assay is not available in many hospitals } \\
\text { - Results need to be interpreted in relation to } \\
\text { the timing of the tablet intake, in accordance } \\
\text { with the pharmacokinetic profile }\end{array}$ \\
\hline $\begin{array}{l}\text { Prothrombin } \\
\text { time }\end{array}$ & $\begin{array}{l}\text { - Measurement of PT with a } \\
\text { reagent sensitive to rivaroxaban } \\
\text { (such as Neoplastin Plus; Roche } \\
\text { Diagnostics, Mannheim, Germany) } \\
\text { may be used for qualitative } \\
\text { assessment only (measured } \\
\text { in seconds) }\end{array}$ & $\begin{array}{l}\text { - Assay is widely available } \\
\text { - Simple assay } \\
\text { - Quick results }\end{array}$ & $\begin{array}{l}\text { - Gives a qualitative assessment expressed } \\
\text { in seconds } \\
\text { - Notable variations with different reagents } \\
\text { - Conventional INR must not be used because } \\
\text { INR does not correct for variations } \\
\text { - The use of PT/INR or CoaguCheck tests } \\
\text { (Roche Diagnostics, Mannheim, Germany) } \\
\text { or PT with insensitive reagents (such as } \\
\text { Innovin }{ }^{\circledR} \text { [Siemens HealthCare Diagnostic } \\
\text { Products GmBH, Marburg, Germany]) } \\
\text { is not recommended }\end{array}$ \\
\hline
\end{tabular}

Note: Data from references 2, 19, 49, and 55.

Abbreviations: INR, international normalized ratio; PT, prothrombin time.

a number of advantages and disadvantages (Table 4) but, importantly, have been shown to provide reliable results. Anti-Factor Xa chromogenic-specific and highly sensitive assays are recommended when quantitative measurements of rivaroxaban exposure are needed. PT is recommended when anti-Factor Xa chromogenic assays are not available and a qualitative measure or rivaroxaban exposure is required. ${ }^{19}$

\section{Conclusion}

AF remains a significant healthcare burden that is expected to increase as the population of the developed world ages. There is a need for effective and convenient oral anticoagulation without requiring routine coagulation monitoring, dose adjustments, or dietary restrictions. Rivaroxaban offers such a treatment option and is indicated in the US and the EU for the prevention of stroke and systemic embolism in patients with nonvalvular AF. ${ }^{2,3}$ The results of the Phase III ROCKET AF study ${ }^{4}$ demonstrated that rivaroxaban $(20 \mathrm{mg}$ once daily, or $15 \mathrm{mg}$ once daily for patients with $\mathrm{CrCl} 30-49 \mathrm{~mL} /$ minute) was noninferior (compared with warfarin) for the prevention of stroke and systemic embolism in patients with nonvalvular AF and a moderate-to-high risk of stroke. Rates of major and nonmajor clinically relevant bleeding were similar in both treatment groups, but there were significantly fewer ICHs and fatal bleeding events in the rivaroxaban group than in the warfarin group. Analyses in patient subgroups - including patients with moderate renal impairment, elderly patients ( $\geq 75$ years), patients with prior myocardial infarction, and patients with prior stroke or TIA - confirmed the overall results of ROCKET AF, demonstrating that rivaroxaban is a valid alternative to warfarin for the reduction of stroke and systemic embolism across a wide range of patients with AF. Despite clear guidance on the use of rivaroxaban for stroke prevention in patients with nonvalvular $\mathrm{AF}$, certain questions, such as the optimal timing of initiation of therapy after stroke, remain unanswered. The large, international GARFIELD (Global Anticoagulant Registry in the FIELD) registry, ${ }^{50}$ which collects real-life management and outcomes of patients newly diagnosed with nonvalvular AF, may provide valuable insight into best practices and treatment options for specific patient subgroups.

\section{Acknowledgments}

The author would like to acknowledge Isabel Ruthven and Claudia Wiedemann, who provided editorial support with funding from Bayer HealthCare Pharmaceuticals and Janssen Research and Development, LLC.

\section{Disclosure}

Dr Turpie has been a consultant to Bayer HealthCare, Janssen Research and Development, LCC, Astellas Pharma, Portola Pharmaceuticals, Inc., and Takeda Pharmaceutical Company Limited. The author reports no other conflicts of interest in this work.

\section{References}

1. Perzborn E, Roehrig S, Straub A, Kubitza D, Misselwitz F. The discovery and development of rivaroxaban, an oral, direct Factor Xa inhibitor. Nat Rev Drug Discov. 2011;10(1):61-75. 
2. Bayer Pharma AG. Xarelto ${ }^{\circledR}$ (rivaroxaban) Summary of Product Characteristics. Leverkusen, Germany: Bayer Pharma AG; 2013. Available from: http://www.ema.europa.eu/docs/en_GB/document_ library/EPAR_-_Product_Information/human/000944/WC500057108. pdf. Accessed August 13, 2013.

3. Janssen Pharmaceuticals, Inc. Xarelto ${ }^{\circledR}$ (rivaroxaban) Full Prescribing Information. Titusville, NJ: Janssen Pharmaceuticals, Inc.; 2011. Available from: http://www.accessdata.fda.gov/drugsatfda_docs/ label/2011/202439s001lbl.pdf. Accessed February 22, 2013.

4. Patel MR, Mahaffey KW, Garg J, et al; ROCKET AF Investigators. Rivaroxaban versus warfarin in nonvalvular atrial fibrillation. $N$ Engl J Med. 2011;365(10):883-891.

5. Lloyd-Jones DM, Wang TJ, Leip EP, et al. Lifetime risk for development of atrial fibrillation: the Framingham Heart Study. Circulation. 2004;110(9):1042-1046.

6. Camm AJ, Lip GYH, De Caterina R, et al. 2012 focused update of the ESC Guidelines for the management of atrial fibrillation: an update of the 2010 ESC Guidelines for the management of atrial fibrillation. Developed with the special contribution of the European Heart Rhythm Association. Eur Heart J. 2012;33(21):2719-2747.

7. Barco S, Cheung YM, Eikelboom JW, Coppens M. New oral anticoagulants in elderly patients. Best Pract Res Clin Haematol. 2013;26(2): 215-224.

8. Wolf PA, Abbott RD, Kannel WB. Atrial fibrillation as an independent risk factor for stroke: the Framingham Study. Stroke. 1991;22(8):983-988.

9. Steger C, Pratter A, Martinek-Bregel M, et al. Stroke patients with atrial fibrillation have a worse prognosis than patients without: data from the Austrian Stroke registry. Eur Heart J. 2004;25(19):1734-1740.

10. Marini C, De Santis F, Sacco S, et al. Contribution of atrial fibrillation to incidence and outcome of ischemic stroke: results from a populationbased study. Stroke. 2005;36(6):1115-1119.

11. Gladstone DJ, Bui E, Fang J, et al. Potentially preventable strokes in high-risk patients with atrial fibrillation who are not adequately anticoagulated. Stroke. 2009;40(1):235-240.

12. Makaryus JN, Halperin JL, Lau JF. Oral anticoagulants in the management of venous thromboembolism. Nat Rev Cardiol. 2013;10(7):397-409.

13. Ageno W, Gallus AS, Wittkowsky A, Crowther M, Hylek EM, Palareti G. American College of Chest Physicians. Oral anticoagulant therapy: Antithrombotic Therapy and Prevention of Thrombosis, 9th ed: American College of Chest Physicians Evidence-Based Clinical Practice Guidelines. Chest. 2012;141(Suppl 2):e44S-e88S.

14. Mercury Pharmaceuticals Ltd. Warfarin $0.5 \mathrm{mg}$ tablets Summary of Product Characteristics. Surrey, UK: Mercury Pharmaceuticals Ltd.; 2013. Available from: http://www.medicines.org.uk/EMC/ medicine/25626/SPC/Warfarin $+0.5 \mathrm{mg}+$ Tablets. Accessed February 5, 2014.

15. You JJ, Singer DE, Howard PA, et al. American College of Chest Physicians. Antithrombotic therapy for atrial fibrillation: Antithrombotic Therapy and Prevention of Thrombosis, 9th ed: American College of Chest Physicians Evidence-Based Clinical Practice Guidelines. Chest. 2012;141(Suppl 2):e531S-e575S.

16. Mahlmann A, Gehrisch S, Beyer-Westendorf J. Pharmacokinetics of rivaroxaban after bariatric surgery: a case report. $J$ Thromb Thrombolysis. 2013;36(4):533-535.

17. Kubitza D, Becka M, Voith B, Zuehlsdorf M, Wensing G. Safety, pharmacodynamics, and pharmacokinetics of single doses of BAY 59-7939, an oral, direct Factor Xa inhibitor. Clin Pharmacol Ther. 2005;78(4):412-421.

18. Kubitza D, Becka M, Wensing G, Voith B, Zuehlsdorf M. Safety, pharmacodynamics, and pharmacokinetics of BAY 59-7939 - an oral, direct Factor Xa inhibitor - after multiple dosing in healthy male subjects. Eur J Clin Pharmacol. 2005;61(12):873-880.

19. Turpie AG, Kreutz R, Llau J, Norrving B, Haas S. Management consensus guidance for the use of rivaroxaban - an oral, direct Factor Xa inhibitor. Thromb Haemost. 2012;108(5):876-886.
20. Kubitza D, Becka M, Roth A, Mueck W. Dose-escalation study of the pharmacokinetics and pharmacodynamics of rivaroxaban in healthy elderly subjects. Curr Med Res Opin. 2008;24(10):2757-2765.

21. Mueck W, Eriksson BI, Bauer KA, et al. Population pharmacokinetics and pharmacodynamics of rivaroxaban - an oral, direct Factor $\mathrm{Xa}$ inhibitor - in patients undergoing major orthopaedic surgery. Clin Pharmacokinet. 2008;47(3):203-216.

22. Mueck W, Borris LC, Dahl OE, et al. Population pharmacokinetics and pharmacodynamics of once- and twice-daily rivaroxaban for the prevention of venous thromboembolism in patients undergoing total hip replacement. Thromb Haemost. 2008;100(3):453-461.

23. Mueck W, Lensing AW, Agnelli G, Decousus H, Prandoni P, Misselwitz F. Rivaroxaban: population pharmacokinetic analyses in patients treated for acute deep-vein thrombosis and exposure simulations in patients with atrial fibrillation treated for stroke prevention. Clin Pharmacokinet. 2011;50(10):675-686.

24. Agnelli G, Gallus A, Goldhaber SZ, et al; ODIXa-DVT Study Investigators. Treatment of proximal deep-vein thrombosis with the oral direct Factor Xa inhibitor rivaroxaban (BAY 59-7939): the ODIXa-DVT (Oral Direct Factor Xa Inhibitor BAY 59-7939 in Patients With Acute Symptomatic Deep-Vein Thrombosis) study. Circulation. 2007;116(2):180-187.

25. Kreutz R. Pharmacodynamic and pharmacokinetic basics of rivaroxaban. Fundam Clin Pharmacol. 2012;26(1):27-32.

26. Fox KA, Piccini JP, Wojdyla D, et al. Prevention of stroke and systemic embolism with rivaroxaban compared with warfarin in patients with non-valvular atrial fibrillation and moderate renal impairment. Eur Heart J. 2011;32(19):2387-2394.

27. Hankey GJ, Patel MR, Stevens SR, et al; ROCKET AF Steering Committee Investigators. Rivaroxaban compared with warfarin in patients with atrial fibrillation and previous stroke or transient ischaemic attack: a subgroup analysis of ROCKET AF. Lancet Neurol. 2012;11(4):315-322.

28. Buller HR, Lensing AW, Prins MH, et al; Einstein-DVT Dose-Ranging Study investigators. A dose-ranging study evaluating once-daily oral administration of the Factor Xa inhibitor rivaroxaban in the treatment of patients with acute symptomatic deep vein thrombosis: the EinsteinDVT Dose-Ranging Study. Blood. 2008;112(6):2242-2247.

29. Halperin JL, Wojdyla D, Piccini JP, Lokhnygina Y, Patel MR, Breinhardt G. Efficacy and safety of rivaroxaban compared with warfarin among elderly patients with nonvalvular atrial fibrillation in the ROCKET-AF trial. Stroke. 2012;43(2_Meeting Abstracts):A148.

30. van Diepen S, Hellkamp AS, Patel MR, et al. Efficacy and safety of rivaroxaban in patients with heart failure and nonvalvular atrial fibrillation: insights from ROCKET AF. Circ Heart Fail. 2013;6(4): 740-747.

31. Mahaffey KW, Wojdyla D, Hankey GJ, et al. Clinical outcomes with rivaroxaban in patients transitioned from vitamin $\mathrm{K}$ antagonist therapy: a subgroup analysis of a randomized trial. Ann Intern Med. 2013;158(12): 861-868.

32. Mahaffey KW, White HD, Nessel CC, et al. Ischemic cardiac outcomes in patients with $\mathrm{AF}$ treated with vitamin $\mathrm{K}$ antagonism or Factor Xa inhibition: results from the ROCKET AF trial. Circulation. 2011;124 (Suppl.):Abstract 13482.

33. Hori M, Matsumoto M, Tanahashi N, et al; J-ROCKET AF study investigators. Rivaroxaban vs. warfarin in Japanese patients with atrial fibrillation - the J-ROCKET AF study. Circ J. 2012;76(9): 2104-2111.

34. Bayer. Xarelto for prevention of stroke in patients with atrial fibrillation (XANTUS). Available from: http://clinicaltrials.gov/show/ NCT01606995. NLM identifier: NCT010606995. Accessed January 8, 2014.

35. Eerenberg ES, Kamphuisen PW, Sijpkens MK, Meijers JC, Buller HR, Levi M. Reversal of rivaroxaban and dabigatran by prothrombin complex concentrate: a randomized, placebo-controlled, crossover study in healthy subjects. Circulation. 2011;124(14):1573-1579. 
36. Perzborn E, Gruber A, Tinel H, et al. Reversal of rivaroxaban anticoagulation by haemostatic agents in rats and primates. Thromb Haemost. 2013;110(1):162-172.

37. Godier A, Miclot A, Le Bonniec B, et al. Evaluation of prothrombin complex concentrate and recombinant activated Factor VII to reverse rivaroxaban in a rabbit model. Anesthesiology. 2012;116(1):94-102.

38. Kaatz S, Kouides PA, Garcia DA, et al. Guidance on the emergent reversal of oral thrombin and factor Xa inhibitors. Am J Hematol. 2012;87 Suppl 1:S141-S145.

39. Lu G, DeGuzman FR, Hollenbach SJ, et al. A specific antidote for reversal of anticoagulation by direct and indirect inhibitors of coagulation Factor Xa. Nat Med. 2013;19(4):446-451.

40. Portola Pharmaceuticals. Phase 2 healthy volunteer study to evaluate the ability of PRT064445 to reverse the effects of several blood thinner drugs on laboratory tests. Available from: http://clinicaltrials.gov/ct2/ show/NCT01758432?term=NCT01758432\&rank=1. NLM identifier: NCT01758432. Accessed January 8, 2014.

41. Johann Wolfgang Goethe University Hospitals. Reversal agent use in patients treated with direct oral anticoagulants (RADOA). Available from: http://clinicaltrials.gov/ct2/show/NCT01722786?term=NCT01722786\& rank=1. NLM identifier: NCT01722786. Accessed February 5, 2014.

42. Gerotziafas GT, Baccouche H, Sassi M, et al. Optimisation of the assays for the measurement of clotting factor activity in the presence of rivaroxaban. Thromb Res. 2012;129(1):101-103.

43. Mani H, Hesse C, Stratmann G, Lindhoff-Last E. Rivaroxaban differentially influences ex vivo global coagulation assays based on the administration time. Thromb Haemost. 2011;106(1):156-164.

44. Asmis LM, Alberio L, Angelillo-Scherrer A, et al. Rivaroxaban: quantification by anti-FXa assay and influence on coagulation tests: a study in 9 Swiss laboratories. Thromb Res. 2012;129(4):492-498.

45. Freyburger G, Macouillard G, Labrouche S, Sztark F. Coagulation parameters in patients receiving dabigatran etexilate or rivaroxaban: two observational studies in patients undergoing total hip or total knee replacement. Thromb Res. 2011;127(5):457-465.

46. Harenberg J, Erdle S, Marx S, Krämer R. Determination of rivaroxaban in human plasma samples. Semin Thromb Hemost. 2012;38(2):178-184.
47. Hillarp A, Baghaei F, Fagerberg Blixter I, et al. Effects of the oral, direct factor Xa inhibitor rivaroxaban on commonly used coagulation assays. J Thromb Haemost. 2011;9(1):133-139.

48. Mani H, Rohde G, Stratmann G, et al. Accurate determination of rivaroxaban levels requires different calibrator sets but not addition of antithrombin. Thromb Haemost. 2012;108(1):191-198.

49. Samama MM, Contant G, Spiro TE, et al. Rivaroxaban Prothrombin Time Field Trial Laboratories. Evaluation of the prothrombin time for measuring rivaroxaban plasma concentrations using calibrators and controls: results of a multicenter field trial. Clin Appl Thromb Hemost. 2012;18(2):150-158.

50. Kakkar AK, Mueller I, Bassand JP, et al; GARFIELD Registry Investigators. Risk profiles and antithrombotic treatment of patients newly diagnosed with atrial fibrillation at risk of stroke: perspectives from the international, observational, prospective GARFIELD registry. PLoS One. 2013;8(5):e63479.

51. Boehringer Ingelheim Pharmaceuticals Inc. Pradaxa ${ }^{\circledR}$ (dabigatran etexilate) Prescribing Information. 2013. Available at: http://www accessdata.fda.gov/drugsatfda_docs/label/2013/022512s0171bl.pdf. Accessed January 28, 2014.

52. Boehringer Ingelheim International GmbH. Pradaxa ${ }^{\circledR}$ (dabigatran etexilate) Summary of Product Characteristics. 2013. Available at: http://www.ema.europa.eu/docs/en_GB/document_library/ EPAR_-_Product_Information/human/000829/WC500041059.pdf. Accessed January 28, 2014.

53. Bristol-Myers Squibb Company, Pfizer Inc. Eliquis ${ }^{\circledR}$ (apixaban) Prescribing Information. 2012. Available at: http://www.accessdata.fda.gov/ drugsatfda_docs/label/2012/202155s0001bl.pdf. Accessed January 28, 2014.

54. Bristol-Myers Squibb, Pfizer EEIG. Eliquis ${ }^{\circledR}$ (apixaban) Summary of Product Characteristics. 2013. Available at: http://www.ema.europa. eu/docs/en_GB/document_library/EPAR_-_Product_Information/ human/002148/WC500107728.pdf. Accessed January 28, 2014.

55. Samama MM, Martinoli JL, Le Flem L, et al. Assessment of laboratory assays to measure rivaroxaban - an oral, direct Factor Xa inhibitor. Thromb Haemost. 2010;103(4):815-825.
Therapeutics and Clinical Risk Management

\section{Publish your work in this journal}

Therapeutics and Clinical Risk Management is an international, peerreviewed journal of clinical therapeutics and risk management, focusing on concise rapid reporting of clinical studies in all therapeutic areas, outcomes, safety, and programs for the effective, safe, and sustained use of medicines. This journal is indexed on PubMed Central, CAS,

\section{Dovepress}

EMBase, Scopus and the Elsevier Bibliographic databases. The manuscript management system is completely online and includes a very quick and fair peer-review system, which is all easy to use. Visit http://www.dovepress.com/testimonials.php to read real quotes from published authors. 